\title{
Impressão 3D de materiais cimentícios: influência da aderência entre camadas nas propriedades mecânicas $\epsilon$ na durabilidade
}

\begin{tabular}{c}
\hline HELENA CARASEK - Doutora/Professora \\
\hline ANDRIELLI MORAIS DE OLIVEIRA - Doutora/ProfeSSORA \\
\hline OSWALDO CASCUDO - Doutor/ProfESSOR \\
\hline PPG-GECON - UnIVERSIDADE FEderal de Golás - UFG
\end{tabular}

\section{RESUMO}

A IMPRESSÃO 3D É UMA FORTE VERTENTE DA INDUSTRIALIZAÇÃO DA CONSTRUÇÃO CIVIL. ESSA TÉCNICA CONSTRUTIVA ENCONTRA-SE EM ESTÁGIO DE DESENVOLVIMENTO E VEM GANHANDO GRANDE ATENÇÃO DO MEIO TÉCNICO DEVIDO ÀS SUAS INÚMERAS VANTAGENS. ESTUDOS TÊM DEMONSTRADO QUE A INTERFACE DAS CAMADAS É O PONTO CRÍTICO ONDE AS PROPRIEDADES MECÂNICAS DECRESCEM. O OBJETIVO DESTE ARTIGO É DISCUTIR ASPECTOS DA INTERFACE DAS CAMADAS GERADAS NAS PEÇAS PRODUZIDAS COM IMPRESSÃO 3D, À BASE DE

\author{
RENATO COSTA ARAÚJO - DoutoRAndo/ProfessoR \\ Instituto Federal de Golás - IFG / PPG-GECON - UFG
}

Palavras-chave: impressão 3D, sistema cimentício, interface, reforço, durabilidade.

\section{INTRODUÇÃO}

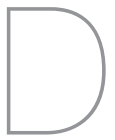

esenvolvida na década de 90 e aprimorada desde então, a impressão 3D com materiais cimentícios proporciona para a construção civil um avanço no processo de industrialização do setor. Neste processo construtivo, os projetos são divididos em camadas por meio de um software e esse sistema operacional envia todas as instruções necessárias para uma impressora, por meio de um arquivo de Código G, que é uma linguagem de programação padronizada para ordenar máquinas a fazer uma atividade.
Existem diversos processos de fabricação em impressão 3D, no entanto apenas dois tipos de tecnologias têm sido aplicados na construção civil: a impressão por extrusão e a por fusão em leito de partícula. A impressão por extrusão consiste em forçar a passagem do material por um bico de impressão, formando um filete de argamassa ou concreto em camadas subsequentes até atingir o formato desejado. A impressão por fusão em leito de partícula baseia-se na deposição de uma camada de areia misturada com óxido de magnésio, empregando-se um agluti- nante de base epóxi ou uma solução de cloreto de magnésio nos pontos onde se deseja causar o endurecimento, processo este repetido, camada por camada, de forma a produzir a geometria almejada. A impressão por extrusão é o método mais disseminado para a construção civil e, portanto, será o abordado neste trabalho.

A extrusão de materiais cimentícios, por vezes, é chamada de impressão 3D do concreto, entretanto o material utilizado na extrusão geralmente é a argamassa (ligantes, areia, água e aditivos, entre outros constituintes). No entanto, 
a proposta da utilização de concreto, que contém o agregado graúdo na sua composição, começa a ser objeto de estudos recentes.

As múltiplas camadas de argamassa na impressão 3D proporcionam ao material um comportamento ortotrópico nas propriedades mecânicas. Assim, essas propriedades no elemento impresso são fortemente influenciadas pela direção da impressão. A fraca ligação entre as camadas da impressão, além de reduzir propriedades mecânicas do material, também pode acarretar redução de sua durabilidade.

Hou et al. (2021) analisaram resultados de diversos trabalhos e demostraram a recorrente anisotropia do material, com a comprovação de que a direção de carregamento com menor resistência à compressão é a paralela às camadas de impressão. Os autores ainda evidenciaram uma redução superior a 58\% para os resultados de resistência à flexão, além de um elevado coeficiente de variação nesta propriedade.

Os fatores que influenciam na impressão 3D podem estar relacionados ao material (composição da argamassa, utilização de fibras, parâmetros reológicos, entre outros), às condições ambientais (temperatura, vento, umidade relativa e tipo de cura) ou ainda aos parâmetros de impressão. Relativo aos parâmetros de impressão, podem ser citados: a velocidade de impressão, o tempo do ciclo de uma camada, o formato e a altura do bico de extrusão, a altura da camada, a geometria do elemento impresso, a tensão de extrusão e a distância de bombeamento da argamassa, além do tipo de mistura, isto porque a mistura intermitente pode aumentar o grau de ortotropia ao longo da elevação das camadas da estrutura (KRUGER; ZIJL, 2021).
Nesse contexto, o presente artigo tem como objetivo discutir, com base em recentes pesquisas publicadas, aspectos gerais da interface das camadas geradas pelo processo de impressão 3D (empregando-se argamassas ou concretos de cimento Portland), os quais se traduzem, em geral, por prejuízos nas propriedades mecânicas e na durabilidade dessas regiões interfaciais e do material como um todo.

\section{INTERFACE DAS CAMADAS}

A interface das camadas impressas com a tecnologia 3D tende a se comportar de forma similar a uma junta fria do concreto aplicado de maneira convencional. Essa é a região com a maior redução das propriedades mecânicas da argamassa e, consequentemente, tornou-se um tema de grande interesse para o desenvolvimento de pesquisas. Nesta perspectiva, foram sintetizadas, a seguir, as principais características e propriedades do filete de argamassa que afetam a ligação entre camadas.

\section{I Umidade superficial da camada}

Um dos aspectos mais elencados nas pesquisas como interveniente na aderência entre as camadas é a perda de umidade superficial. Dessa forma, as condições ambientais exercem grande influência nesta aderência, colaborando com a evaporação de água presente na mistura. Outro importante fator é o intervalo de tempo transcorrido entre a deposição das camadas, pois quanto maior for o período decorrido maior será a evaporação e também maior será o consumo da água da mistura pela hidratação do cimento na camada já depositada (BADUGE et al., 2021).
Algumas pesquisas realizadas demostraram que uma camada protegida da secagem, mesmo quando exposta por até duas horas antes de receber a próxima camada, não apresenta relevante alteração na resistência de aderência da interface. Entretanto, quando a camada fica exposta à ação do vento, há reduções consideráveis da aderência após um período de apenas 10 minutos de exposição (KRUGER; ZIJL, 2021). Por fim, analisando a resistência de aderência, o intervalo de 35 minutos foi estabelecido com o tempo ótimo entre a deposição de duas camadas (KHAN et al., 2020).

A depender das configurações da impressão 3D, a perda da umidade na superfície das camadas impressas pode levar à redução de até 75\% da resistência na interface em um período de apenas 60 minutos de exposição (KRUGER; ZIJL, 2021). Pesquisas que investigaram um período de tempo mais longo, como 24 horas, afirmaram que, em situações extremas, essa redução pode atingir níveis de 92\% (KHAN et al., 2020).

A perda da umidade ainda pode influenciar na porosidade e na distribuição dos poros dentro das camadas impressas. Investigações têm demostrado que quando a deposição das camadas ocorre sem intervalo de tempo a porosidade global é reduzida; no entanto, quando se aumenta o intervalo de tempo de deposição entre as camadas, a porosidade do material no geral aumenta, principalmente nas interfaces, devida à perda de umidade. Ademais, a interface torna-se uma região ainda mais vulnerável, uma vez que a porosidade ocasiona a redução da resistência mecânica (MOHAM et al., 2021). 


\subsection{Rugosidade da superfície da camada}

A aderência na interface dependerá também da rugosidade da camada anterior, assim como da camada subsequente. Estudos evidenciam que velocidades de impressão mais baixas proporcionam maior rugosidade para o filete impresso, resultando dessa forma em um aumento significativo da resistência de aderência na interface.

A correlação inversa entre velocidade e rugosidade está associada ao fato de uma velocidade elevada promover
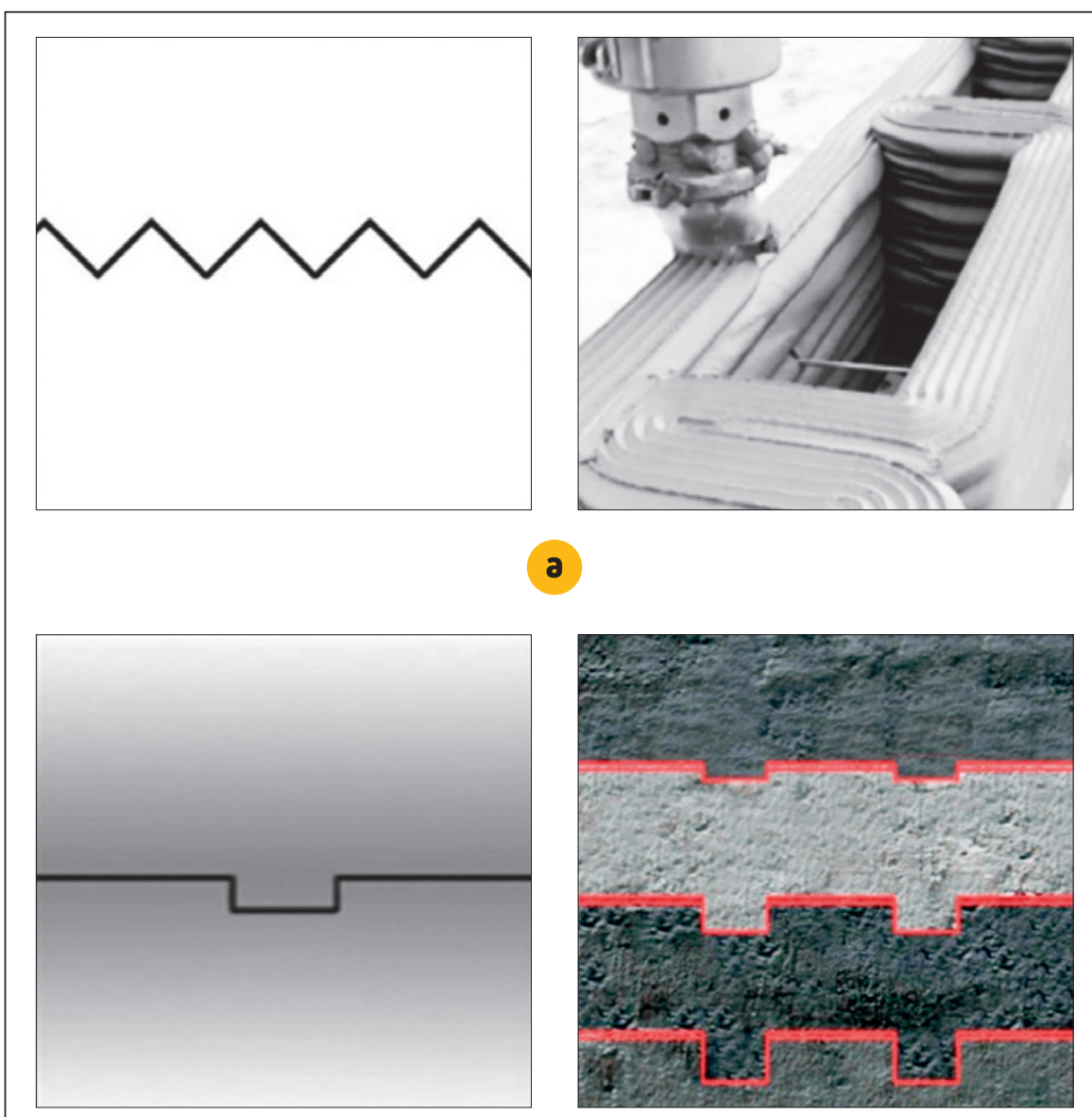

a

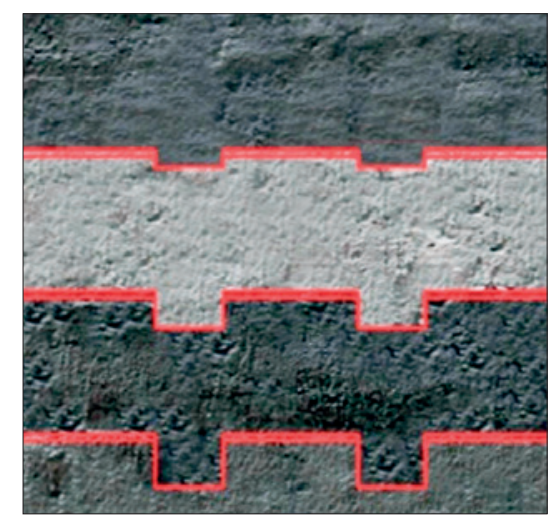

b

Figura 1

Técnicas utilizadas na impressão 3D para alterar a rugosidade entre camadas: (a) Bico serrilhado; (b) Encaixe macho/fêmea

Fonte: adaptado de Baduge et al. (2021) e Moham et al. (2021) uma altura superior à altura da camada (KHAN et al., 2020).

A Figura 1 apresenta duas técnicas abordadas por Baduge et al. (2021) para aumentar a rugosidade superficial da camada adjacente, de forma a melhorar as propriedades da interface. Um dos métodos é o uso de bico serrilhado, de modo a gerar uma irregularidade na superfície da camada; o estudo indicou um aumento de $21 \%$ na resistência da ligação entre as camadas com o emprego dessa técnica (Figura 1a). O outro método consiste na impressão de um filete onde na parte superior da camada há uma reentrância e na parte inferior há uma saliência. Este formato é chamado de encaixe macho-fêmea, o que produz melhorias potenciais da ordem de $25 \%$ na resistência à tração entre as camadas (Figura 1b).

\subsection{Retração $\in$ fissuração}

Algumas características da tecnologia 3D geram condições de maior susceptibilidade à retração, tais como: o material empregado na impressão possui um elevado consumo de cimento e, em geral, não contém agregados graúdos, além de não serem empregadas fôrmas no processo (não havendo nenhuma proteção para a saída da água).

As retrações plásticas, por secagem ou autógenas podem resultar no surgimento de fissuras, formando uma região de concentração de tensão e, consequentemente, de laminação entre as camadas, fragilizando assim a interface. Além da redução das propriedades mecânicas, as fissuras poderão ser facilitadoras para a entrada de agentes agressivos, podendo, a longo prazo, reduzir a durabilidade desse sistema construtivo (HOU et al., 2021; MOHAM et al., 2021; BADUGE et al., 2021). 


\section{REFORÇOS}

Como visto, a interface das camadas na impressão 3D é uma zona de menor resistência mecânica, requerendo então atenção. Uma alternativa visando à melhoria dessa região é a utilização de reforços localizados, os quais podem ser inseridos durante a impressão ou mesmo posteriormente a esse processo.

Alguns pesquisadores estudaram a potencialidade de diferentes métodos e encontraram como os dois mais promissores: a) a inserção de fibras na argamassa durante a mistura (Figura 2a); e b) o reforço com cabo de aço flexível inserido durante a impressão (Figura 2b). Uma desvantagem recorrente em vários métodos de reforço é a redução da liberdade geométrica durante a impressão 3D (MOHAM et al., 2021).

O tipo de reforço mais difundido é aquele que incorpora fibras durante o processo de mistura da argamassa fresca (Figura 2a). Nesse sentido, visando à sua execução, têm sido empregadas fibras curtas de materiais diversos, tais como: aço, vidro, basalto, carbono, acetato de polivinila, polipropileno e polietileno.

No estudo apresentado por Khan et al. (2020), a inserção de 1\% de fibras de aço em volume possibilitou o aumento de até 20\% da resistência à tração. Contudo, é de conhecimento que a adição de fibras pode reduzir a trabalhabilidade da argamassa. Nesse sentido, o mesmo estudo menciona que a adição de 1\% de fibras de aço reduziu $4 \%$ da trabalhabilidade e 0,5\% de fibra de polipropileno reduziu $33 \%$ da trabalhabilidade. Portanto, há que se considerar os efeitos positivos e negativos dessas incorporações, realizando-se os devidos estudos de compatibilidade e de viabilidade técnica de execução, para se poder adotar o reforço mediante fibras, sem prejuízo reológico ou com mínimos impactos neste sentido.

Outro reforço possível é o uso de cabo de aço, inserido durante a im-

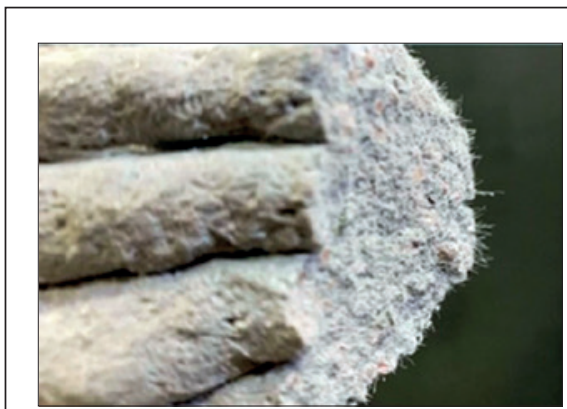

a

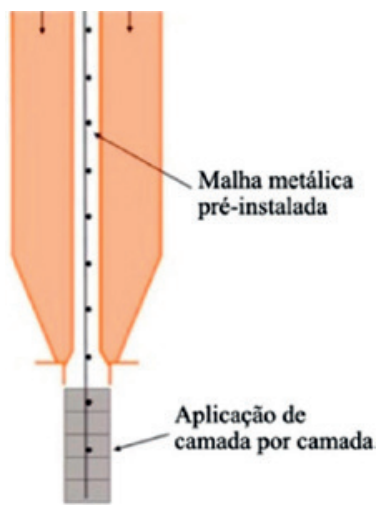

c

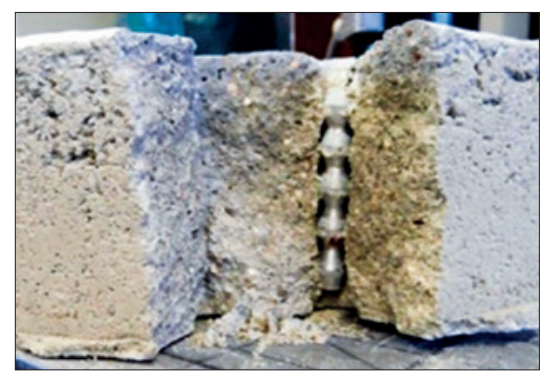

e pressão (Figura 2b). Neste caso, um bico auxiliar é acoplado na impressora e tem a função de puxar o cabo de uma bobina e incorporá-lo na camada de argamassa que passou pelo processo de extrusão. Além disso, uma possibilidade adicional de reforço é a pré-instalação manual de tela; neste

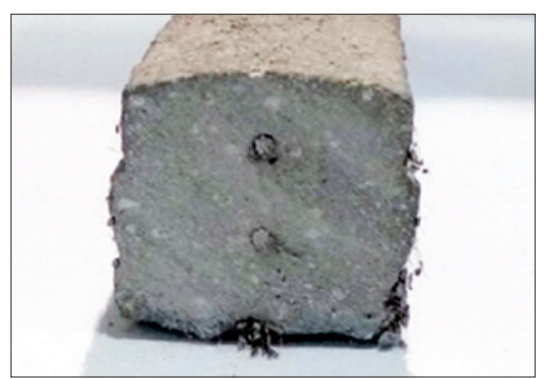

b

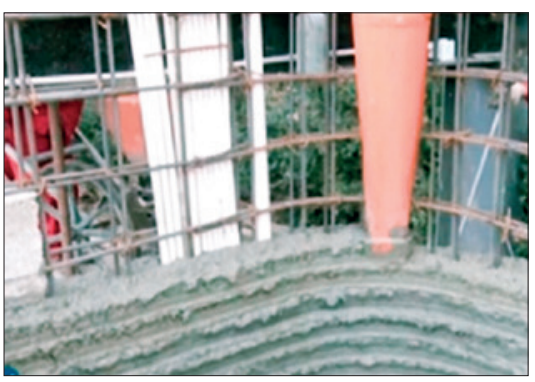

d

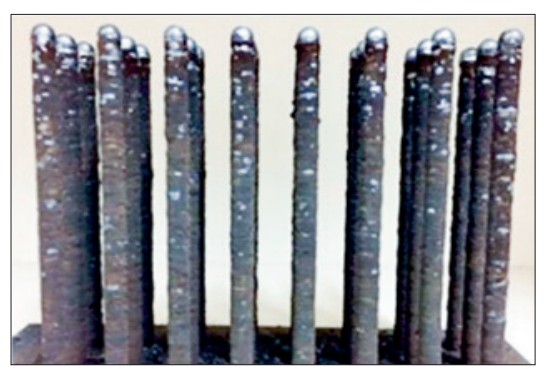

f
Figura 2

Técnicas de reforço da impressão 3D: (a) Argamassa com fibra; (b) Uso de cabo de aço flexível; (c) e (d) Reforço com malha metálica; (e) Impressão síncrona de argamassa e metal; (f) Impressão de barras metálicas Fonte: Moham et al. (2021) 
caso, é utilizado um bico duplo adaptado para a execução da impressão (Figuras 2c e 2d).

Uma alternativa que está em desenvolvimento é a impressão de reforço metálico de forma síncrona com a impressão de argamassa (Figura 2e). A impressão do metal pode ser realizada por técnica de soldagem a arco ou por fusão de um feixe de laser em leito de pó, dando origem a trechos de barras metálicas impressas (Figura 2f). Porém, o método ainda apresenta limitações, como custo elevado, baixa velocidade e elevada temperatura da impressão do metal, o que pode alterar a argamassa, trazendo prejuízos a ela. Os métodos de impressão simultânea de argamassa com reforço metálico ainda precisam ser aperfeiçoados (BADUGE et al., 2021).

A utilização do cabo de aço flexível como reforço pode aumentar a resistência à tração da peça de impressão 3D em até $290 \%$. Há possibilidade de incorporar o reforço metálico externo à argamassa após o processo de impressão, conforme ilustra a Figura 3a. Outra possibilidade de aplicação de reforço após a impressão é a protensão aplicada em peças pré-moldadas impressas em 3D (Figura 3b).
Outro tipo de reforço aplicado à impressão 3D de materiais cimentícios é a aplicação de um agente de ligação entre as camadas de impressão. Este pode ser realizado com uma pasta de cimento adicional, argamassa com resina epóxi ou polímero à base de látex. A vantagem é que esse método pode ser facilmente incorporado ao processo de impressão pela utilização de dois bicos de impressão (Figura 4).

\section{DURABILIDADE}

Assim como a caracterização nos estados fresco e endurecido, os aspectos relacionados à durabilidade dos elementos impressos pela tecnologia 3D são aferidos por meio de métodos desenvolvidos para o concreto convencional. Pesquisas experimentais compararam o transporte de água no concreto convencional e no impresso em 3D. No concreto convencional, de forma clássica, o transporte de íons em meio aquoso ocorre inicialmente por absorção e, posteriormente, o movimento atua por difusão, de forma relativamente lenta. $\mathrm{Na}$ argamassa impressa em 3D, houve uma forte absorção que resultou na entrada da água em uma velocidade maior do que no concreto convencional, absorção esta causada pela sucção da água devido ao sistema de poros intrínseco (típico) da estrutura impressa (MOHAM et al., 2021).

O transporte de líquidos e gases na argamassa impressa 3D é mais propício. Na Figura 5, está ilustrada a hipótese de transporte iônico dentro dessa estrutura. A estrutura do material produzido em camadas, onde as interfaces apresentam maior porosidade, resulta em uma rápida absorção e sucção capilar (Figura 5b). Após saturar rapidamente, o transporte iônico para o interior dos filetes de argamassa, nessa estrutura de poros interconectados, ocorrerá de forma similar ao que ocorre com o concreto convencional, principalmente pela difusão (Figura 5c). Como as argamassas utilizadas na impressão 3D geralmente apresentam baixa relação água/ligante, com incorporação de adições minerais, essa última etapa do transporte deveria ocorrer lentamente. Contudo, os filetes são estruturas geralmente delgadas e a área superficial em contato com os agentes agressivos é consideravelmente maior (KRUGER; ZIJL, 2021; HOU et al., 2021).

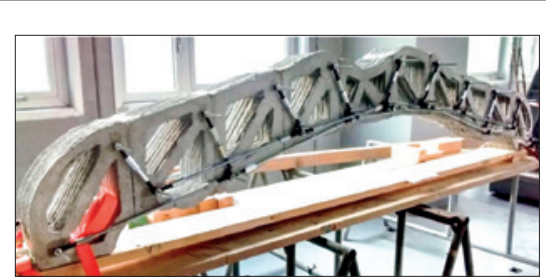

a

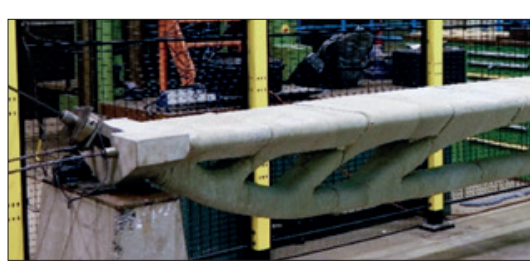

b

Figura 3

Técnicas de reforço aplicadas após a impressão 3D: (a) Treliça com reforço metálico externo; (b) Protensão

Fonte: Moham et al. (2021)

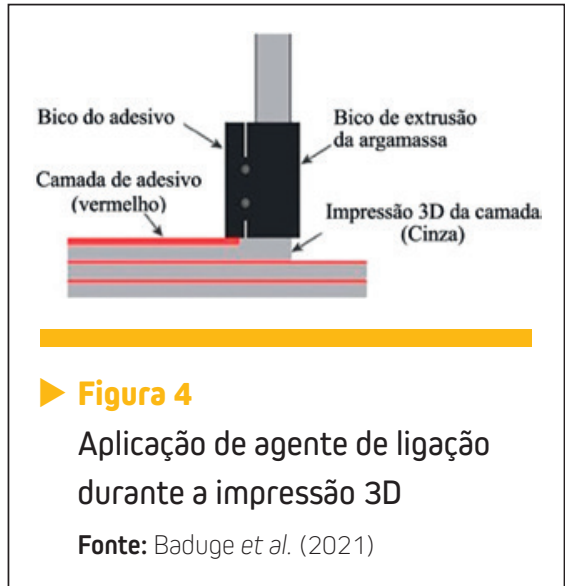




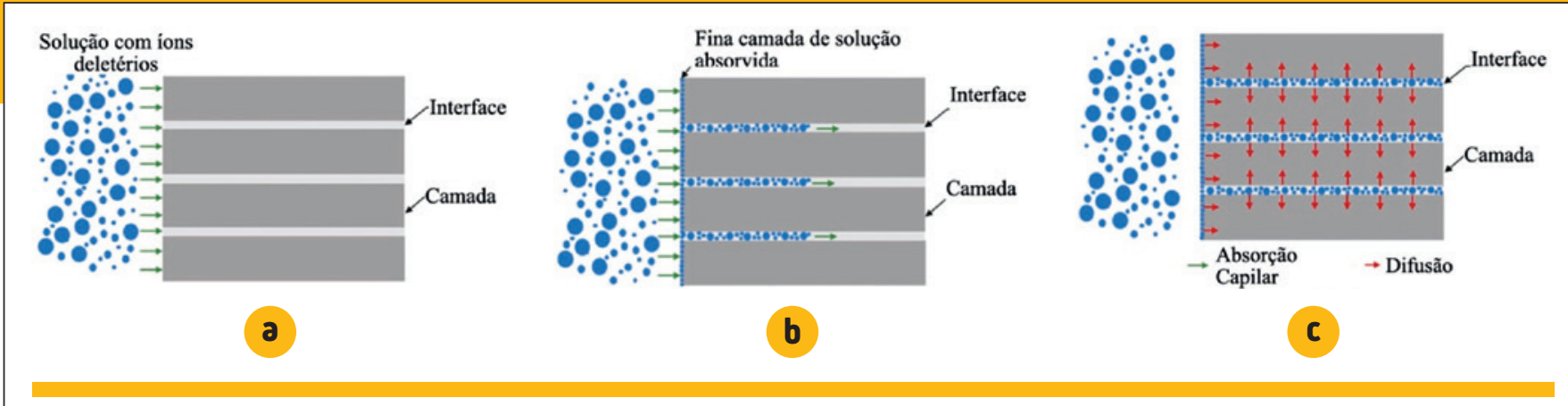

Figura 5

Simulação de transporte iônico na impressão 3D: (a) Contato com íons deletérios; (b) Absorção por capilaridade; (c) Difusão

Fonte: Moham et al. (2021)

De forma similar à molhagem, a secagem ocorrerá sem grandes dificuldades, causando assima dessorção. Esse sistema de poros indica a vulnerabilidade da argamassa de impressão 3D para ciclos de molhagem e secagem, pois haverá uma maior tendência de deterioração das interfaces das camadas. A entrada facilitada de íons deletérios, seguida pela secagem (que também ocorre sem grandes dificuldades), pode aumentar rapidamente a concentração desses íons durante os ciclos de molhagem e secagem, propiciando maior deterioração. Ademais, os ciclos de molhagem e secagem podem levar à microfissuração por fadiga, devida à ocorrência de repetidos ciclos (MOHAM et al., 2021).

Os principais parâmetros de durabilidade estão relacionados com o mecanismo de transporte dentro do material, pois este influencia a resistência aos ataques por penetração de cloretos, a ação da carbonatação, os ciclos de gelo-degelo e a reação álcali-agregado, entre outros.

A carência de estudos experimen- tais sobre a durabilidade dos materiais de impressão 3D para a construção civil evidencia a necessidade de avanços na fronteira do conhecimento, mediante a realização de pesquisas aplicadas em laboratório e em campo voltadas à estimativa de vida útil e à durabilidade de edificações, em geral considerando diferentes ambientes agressivos e condições climáticas, tendo em vista essa nova perspectiva de construção.

\section{CONSIDERAÇÕES FINAIS}

Estudos das propriedades mecânicas evidenciam que a ligação entre as camadas da impressão 3D resulta em uma região de menor resistência mecânica, gerando no conjunto impresso uma estrutura ortotrópica. As principais características da argamassa impressa que afetam a interface são: umidade e rugosidade superficial da camada, além de fissuração por retração. Esses fatores podem levar à redução das propriedades mecânicas na ligação entre as camadas em mais de $90 \%$.
Uma solução viável para redução do comportamento ortotrópico é o uso de algum reforço, como adição de fibras curtas na mistura de argamassa fresca ou a inserção de cabo de aço flexível durante a impressão. As fibras levam, em geral, à redução da trabalhabilidade, porém podem melhorar em até 20\% as propriedades mecânicas da interface.

A utilização de reforços metálicos como telas, cabos e barras em elementos impressos em 3D favorece a produção de estruturas com melhores propriedades mecânicas. Entretanto, a presença de um material metálico no interior da argamassa traz à tona a preocupação com a durabilidade, especificamente com a corrosão metálica. Isto porque a estrutura porosa do material impresso global (considerando todas as camadas e suas interfaces) é normalmente superior a de outros materiais cimentícios (como o concreto plástico convencional de elementos estruturais contínuos), o que pode facilitar a entrada de agentes agressivos e o desenvolvimento precoce de manifestações patológicas.

\section{DREFEÊNCIAS BIBLIOGRÁFICAS}

[1] KRUGER, J.; ZIJL, G. A compendious review on lack-of-fusion in digital concrete fabrication. Additive Manufacturing. 37, 21 p, 2021.

[2] HOU, S. et al. A review of 3D printed concrete: Performance requirements, testing measurements and mix design. Construction and Building Materials. 273, 19p, 2021.

[3] MOHAM, M. K. et al. Extrusion-based concrete 3D printing from a material perspective: A state-of-the-art review. Cement and Concrete Composites. 115, 17p, 2021

[4] BADUGE, S. K. et al. Improving performance of additive manufactured (3D printed) concrete. Structures. 29, 12p, 2021

[5] KHAN, M. A. Mix suitable for concrete 3D printing: A review. Materials Today: Proceedings. 32, 6p, 2020. 